\title{
DETERMINING INFORMATION SYSTEMS PROCUREMENT STRATEGY - AHP APPROACH
}

\author{
Petri Hallikainen and Hannu Kivijärvi \\ Helsinki School of Economics and Business Administration \\ P.O. Box 1210, 00100 Helsinki, Finland \\ Petri.Hallikainen@hkkk.fi / Hannu.Kivijarvi@hkkk.fi
}

\begin{abstract}
We address the problem of selecting the appropriate information system procurement strategy. Basically, a company can select between three alternatives: software package, tailored package, and in-house development. A Substance-Theory-Oriented approach is applied to construct an AHP hierarchy at general level to be used in assessing the procurement alternatives. The theories refer to some managerial theoretical constructs found in respective economic, managerial, and IS literature. We emphasize on using a broad set of evaluation criteria and making sensitivity analysis when comparing the different procurement alternatives. A case experiment is conducted to illustrate the application of the proposed evaluation methodology to determining the appropriate procurement strategy.
\end{abstract}

\section{Introduction}

Companies are investing extensive amounts of money in information systems (IS) (Digital Planet, 1988). There are many kinds of benefits a company can gain from IS investments: increased revenues, cost savings, better quality of internal functions in the company, better decision support, and improvement in the competitive position of the company. It has been argued in several studies that the extensive use of information systems leads to increasing organizational efficiency, performance and success. On the other hand, a number of studies have failed to found such a positive relation or there are studies that have even found some opposite evidence (Brynjolfsson, 1993, Brynjolfsson and Hitt, 1998).

It is obvious that information system investments can bring substantial benefits to companies, but on the other hand, there are also many risks involved, and the possible failures can cause serious problems. Furthermore, the strategic effects of IS investments are not, in many cases, taken into account when evaluating IS investments. Because IS investments can have dramatic effects on the survival of companies, the task of evaluating information system projects should be done very carefully in order to ensure appropriate decisions.

One of the most critical decisions when managing an IS development project is deciding about the procurement strategy. Basically a company can choose from three procurement strategies: 1) developing the system in-house; 2) letting a software vendor develop the system; and 3) buying a software package "from the shelf". According to Saarinen and Vepsalainen (1994) procurement means the choice among suppliers (in-house personnel, outside experts, consultants, software contractors, or package dealers) and contracting forms (salary, project contract, package price, lease or rent). They state that the main problem, in practice, is choosing the correct procurement strategy so that the most appropriate developer team is assigned for each project. According to their procurement principle for choosing the efficient procurement strategy routine systems can be best implemented by acquiring software packages from implementors, standard applications require software contracting by analysts and possibly other outside resources for implementation, and speculative investments are best left for internal development by innovators.

In this study we aim to develop a concrete tool for companies to support decision making about IS procurement strategies. Our reasoning starts with the special characteristics of IS investments, especially 
emphasizing the strategic importance and the risks involved in these projects. The emphasis in our analysis is to use a broad set of criteria and to make sensitivity analysis when evaluating different options.

In the next section we address the question of the special nature of IS investments and the kind of implications it has for the evaluation of the procurement strategies. In the third section we present a model for analyzing the candidate strategies and making the final decision for system procurement using the AHP.technique. Finally, the conclusions are drawn in the fourth section.

\section{Information systems evaluation}

\section{Background}

A feasible starting point for evaluating any investment is to consider the investment's revenues and risks (Markowitz, 1952). However, IS investments have some special characteristics that make it very complicated to evaluate their costs - and especially their benefits. First, they are intangible in nature (see e.g. Powell 1992, Kivijärvi and Tuominen 1999). In many cases monetary measures cannot be used, but subjective arguments have to be applied also. Second, the benefits of IS investments are realized during a long period of time. Thus, using only traditional investment evaluation techniques for evaluating these investments is not sufficient. Most of the traditional investment criteria imply that the initial investment, the incremental cash flows, cost of capital, and the economic time horizon of the investment alternative are known. It is assumed that all the effects of the investment can be traced, measured, and transformed into monetary units. Intangible costs and revenues are assumed to be zero and subjective criteria are ignored. Third, in IS investments, the benefits are seen differently by different interest groups (Farbey et al., 1992). Fourth, these investments evolve over time and get entangled to each others (see e.g. Dos Santos, 1991). Fifth, IS investments are irreversible in nature (PCs, see Heikkila, 1995). Moreover, the risks of IS investments are exogenous and uncontrollable (Clemons et al, 1995).

Some suggestions how to handle the problematics of evaluating IS investments have been presented in the literature (Wehrs 1999). Keeping in mind the different stakeholders, Peffers and Saarinen (1993) presented the following five broad criteria for evaluating IS investments: strategic value, financial profitability, risk, success of development process, and successful use of the system. Furthermore, management theory about IS evaluation suggests that these investments should be evaluated in all phases of the system's life cycle (Lester and Willcocks, 1993).

Keeping the special characteristics of IS investments and the need to evaluate in all phases of the system's life cycle in mind, an appropriate evaluation methodology should allow changing the evaluation criteria, or their weights, when evaluating in different phases of the system's life cycle. Moreover, the methodology should allow to include subjective measures in addition to "hard" monetary measures. Also, it should allow to perform sensitivity analysis.

\section{Hierarchy construction}

One potential approach to evaluate IS procurement strategies is to measure their impacts by utility concept as concretized by the principles of Analytic Hierarchy Process. AHP is a general decision-making tool that can be used to evaluate discrete alternatives, which may include subjective or intangible criteria (Saaty, 1999). The main advantage of the approach is that the different criteria with divergent measures can be transformed easily into a single utility measure. The key conceptual tool of AHP is the goal hierarchy where the relations between the goals are described. The additive aggregation rule behind the hierarchy makes it easy to understand the principle of the decomposition and the results. In IS-literature, Santhanam and Guimares (1995) applied AHP to the problem of evaluating the quality of institutional Decision Support Systems. Wen and Sylla (1999) developed an hybrid model were AHP is integrated to a goal programming model in order to quantify subjective intangible benefits and risk factors involved IT investments. 
Because the design of the AHP-hierarchies requires knowledge and experience of the specific problem area the hierarchies are usually not general. Here, a Substance-Theory-Oriented approach (Kivijärvi, 1997) is used to construct the AHP hierarchy partly at a general level. The theories refer to some managerial theoretical constructs found in respective economic, managerial, and IS literature. Our purpose is to proceed in two phases. First, we develop an evaluation principle at general level and then define the lower level, problem specific measures. The set of general evaluation criteria is shown in Table 1.

The main criterion in our model is the success of an information system project. Every investment in an organization should contribute to the goals of that organization. The success of an information system investment might be described as the extent to which the expected benefits have realized and whether the development process has proceeded according to plans.

Table 1 General criteria for evalauting IS project success

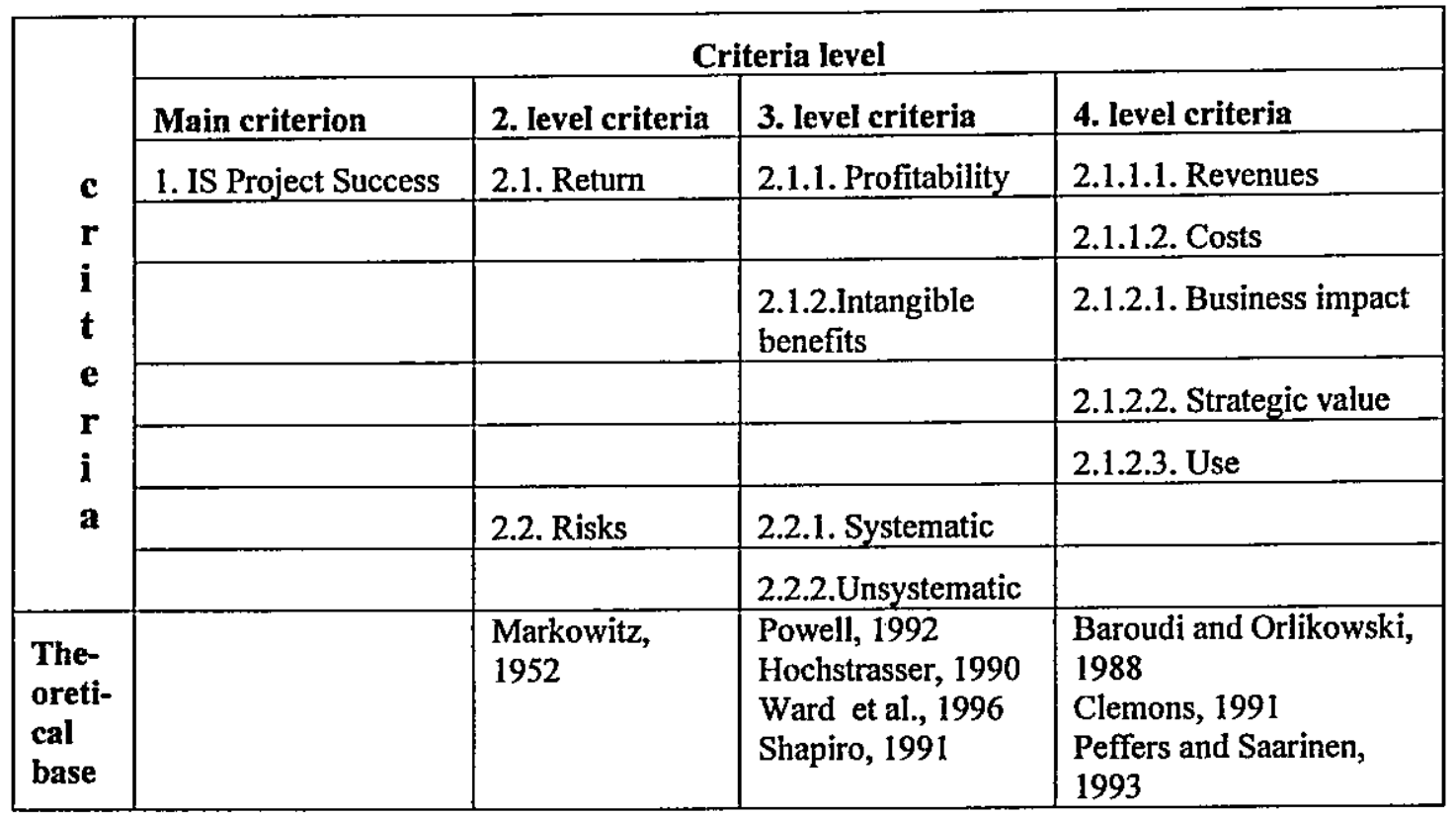

The second level criteria in our model are return and risk. These criteria are widely accepted as a basis for evaluation of any portfolio of investment alternatives (Markowitz, 1952). At the third level in our model we divide return to two sub-criteria: profitability and intangible benefits. By profitability we mean the benefits gained from the investment that can be measured in monetary terms. The intangible benefits criterion, on the other hand, includes the intangible benefits. The benefits gained from information system investments are often intangible and very difficult to express in monetary terms (Powell, 1992). Furthermore, we divided risk to systematic and unsystematic. Systematic risk stems from outside of the company and unsystematic from inside of the company (Shapiro, 1991).

At the fourth level of our model we divided other benefits further to business impact, strategic value and use (Peffers and Saarinen, 1993). Nowadays, information system investments are often strategic in nature (Clemons, 1991), and in many cases they have a central role in streamlining the companies' business functions. The successful use of the system has been addressed in many studies about user information satisfaction (Baroudi and Orlikowski, 1988). Moreover, we divided profitability further to revenues and costs. 


\section{A descriptive experiment}

We use a large Finnish company from insurance and banking industry as a reference in our experiment. The company faced an actual decision situation when selecting a procurement strategy for an information system that was meant to be a pilot project to gain experience about an entirely new business area. The aim of the project was to offer customers new kinds of services. The procurement alternatives considered were in-house development using company's own resources, acquiring a tailored software package from an outside vendor, and buying a software package "from the shelf".

\section{Final hierarchy with respective measures}

In this case, the analytic hierarchy process (AHP) is used to select the appropriate information system procurement strategy. Here, AHP is used to assist decision makers in obtaining a detailed understanding of how the preference judgements concerning the relative importance of attributes influence their choice of the strategy. According to the principles of AHP, the initial decision problem is first decomposed into subproblems in a hierarchical fashion. Then the priorities of the elements at each level of the decision hierarchy are determined. Finally, the priorities are synthesized in order to determine the overall priorities of the alternative procurement strategies.

Figure 1 Final hierarchy with local weights

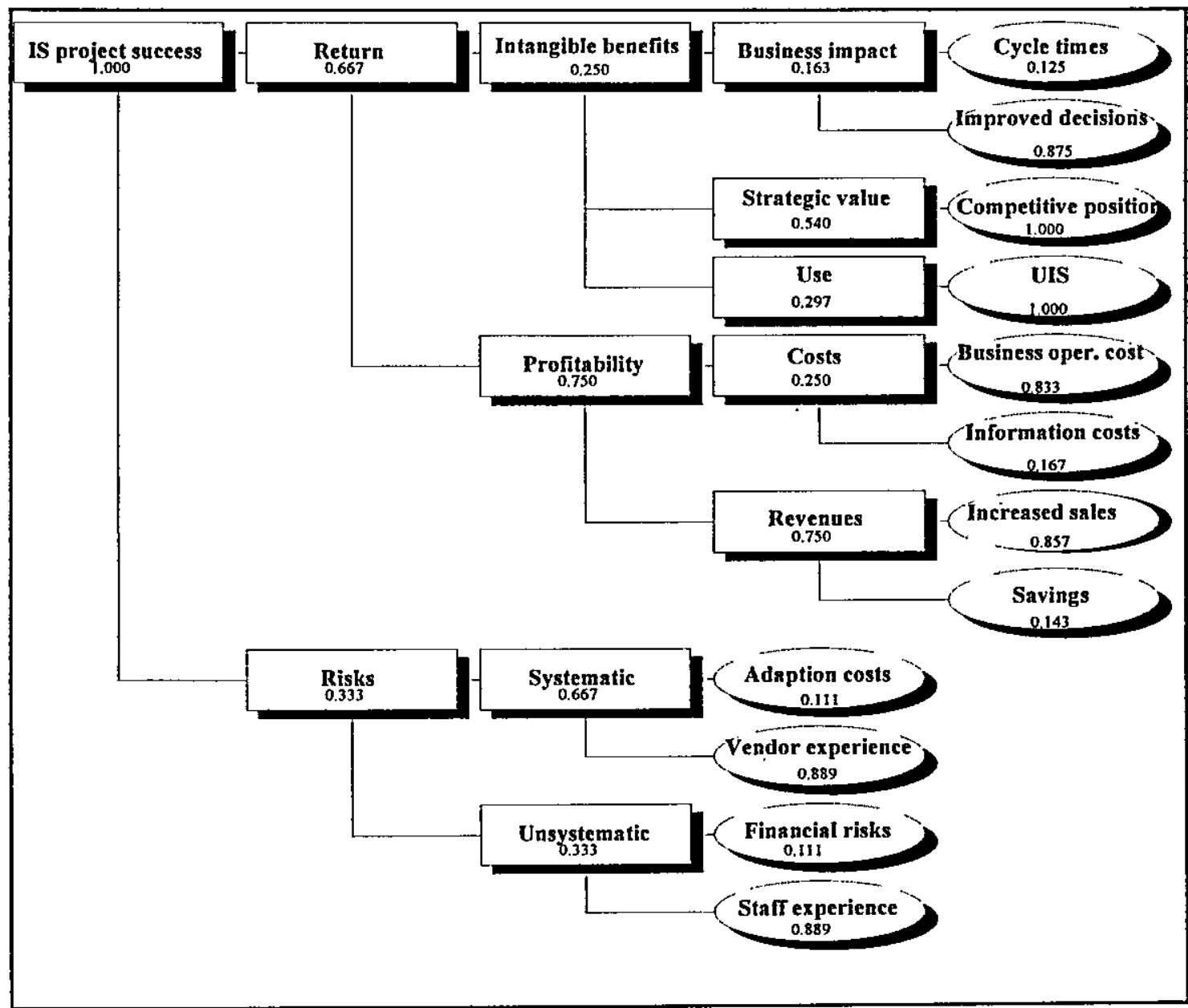


In our case, although, it seems that there are a great many potential measures to be used as a goal variable (decision criterion) for the evaluation of the effects of the procurement strategies. We decided to apply the evaluation hierarchy directly as proposed in the previous section. At the lowest (operational) level we used 12 measures. For the measurement of business impacts we used cycle times and improved decisions. The strategic value of IS is measured by the competitive position of the corporation. The quality of the potential system is evaluated by UIS-measurement instrument (User Information Satisfaction). Costs are further divided into business operation costs and information costs. Information costs are assumed to include also the initial license fee, maintenance, and resource utilization. The revenues are assumed to come from the increased sales and cost savings. Systematic (external) risks are measured by vendor experience and adaptation costs (e.g. costs due to changing the technological platform). Unsystematic risk includes financial risks and staff experience. It should be noted that most of the measures are perceived, subjective evaluations, not precise quantitative measures.

The final set of relevant criteria with respective measures is presented in a vertical fashion in Figure 1. At the top of the hierarchy lies the most general objective of a decision problem. The lower level of the hierarchy contains the other criteria as discussed above. The three decision alternatives, Tailored package, In-house developed System, and Software package, are not included in the figure. A comparison of the elements in pairs at each level produces the order of the relative importance of each element with respect to the criterion above. By comparison it is possible to proceed according to top-down or bottom-up principles. After making all other comparisons in pairs, it is possible to calculate the results.

\section{Results}

After making all paired comparisons it is possible to compute the results. Figure I indicates that at the second level Return (0.667) is more important than Risk (0.333). Systematic risk is evaluated to be more important than unsystematic risk. The total priorities of strategies are synthesized in Figure 2. The tailored package seems to be the best alternative with respect to the criteria mentioned above.

Figure 2 Final ranking of the procurement strategies

\section{Ranking for IS project success}

\begin{tabular}{|lc} 
Alternative & Utility \\
Tailored package & 0.478 \\
In-house devel. system & 0.380 \\
Software package & 0.142
\end{tabular}

Using sensitivity analysis we can study how sensitive the alternatives are to the changes in importance of the criteria. For example Figure 3 shows the sensitivity analysis of the results with respect to the importance of the business operation costs criterion. The graph displayed shows that the current priority for the criterion is $\mathbf{0 . 1 0 4}$ (see vertical dashed line). The height of the intersection of this dashed line with alternative lines shows the priorities of the alternatives. Now the tailored package is the preferred alternative. If business operation costs criterion becomes more important then software package would be the preferred alternative.

When all the strategies are analyzed the final results are calculated and they can be grouped into a portfolio matrix (Figure 4). The position of each alternative in the matrix is determined directly by the coefficients of risk and expected return (Kivijärvi and Tuominen, 1998). According to Figure 4, only Inhouse developed system and Tailored package are efficient Pareto solutions to the initial problem. 
Figure 3 Sensitivity analysis for business operation costs

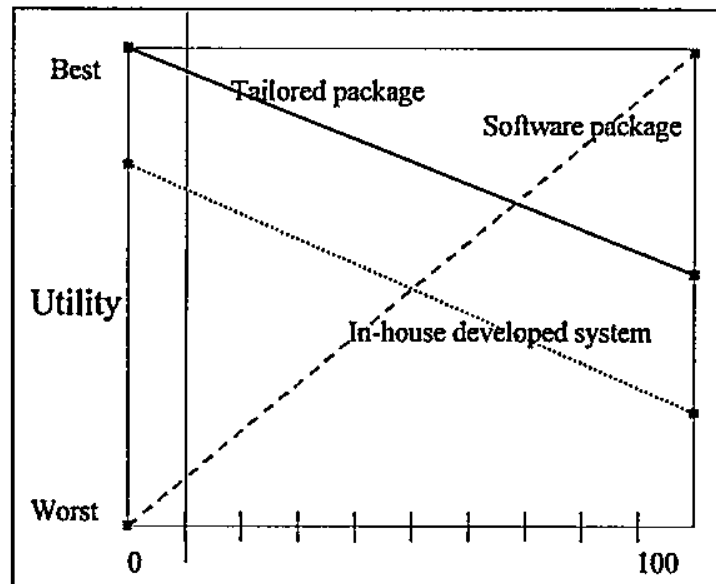

Percent of Weight on Business operation costs Measure
Figure 4 The portfolio of investment alternatives

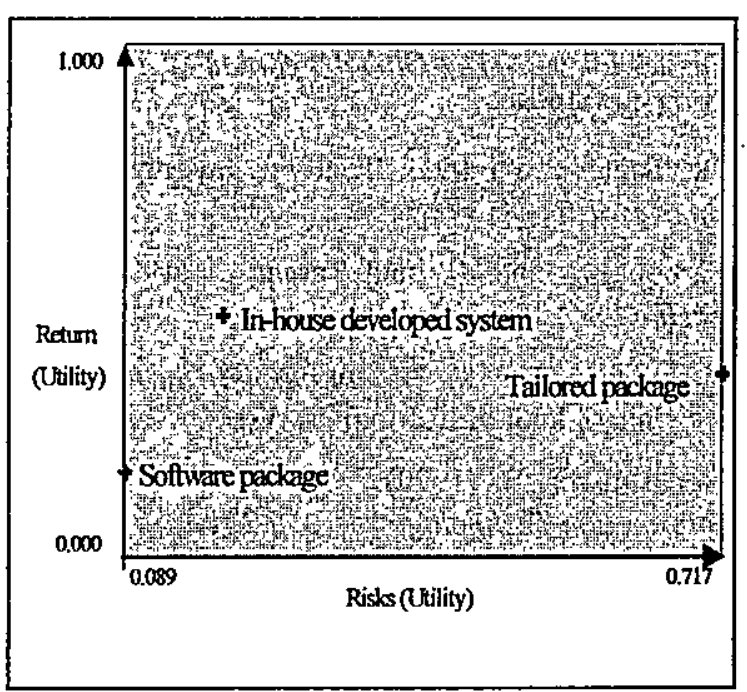

\section{Discussion and conclusion}

In this study have developed a concrete tool for companies to support decision-making concerning IS procurement strategies. We start with the special characteristics of IS investments, especially the strategic importance and the risks involved in these projects. We developed an evaluation principle first at general level and then we defined the lower level, problem specific measures. As a constructive case, we used data from a reference company to illustrate how our hierarchical evaluation technique can be used to assist in decision making when selecting the procurement strategy.

The methodology we propose for IS evaluation has several advantages. First, it allows the comparison of intangible criteria. As stated in information system management theory this is essential when evaluating IS investments. Second, sensitivity analysis can be conducted easily. Third, the proposed approach is cost effective. It is much easier to adapt the general valuation methodology to a specific circumstance than to build a whole unique evaluation procedure from the beginning. The trend nowadays is towards networked IS-development. This kind of methodology can be effectively used for making comparisons between different strategies, vendors, and development strategies. We believe that the proposed approach to evaluate information systems has high potential in practice.

\section{References}

Baroudi, J., J. \& Orlikowski, W., J. (1988)., "A Short-Form Measure of User Information Satisfaction: A Psychometric Evaluation and Notes on Use", Journal of Management Information Systems, 4, 44-59.

Brynjolfsson, E. (1993), "The Productivity Paradox of Information Technology", Communication of ACM, $36,67-77$

Brynjolfsson, E. and Hitt, L.M. (1998), "Beyond the Productivity.Paradox", Communication of ACM, 41, 49-55.

Clemons, E., K. (1991), "Investments in Information Technology”, Communications of the ACM, 34, 23-36. 
Clemons E.K., Thatcher M.E., and Row M.C. (1995), "Identifying Sources of Reengineering Failures: A Study of the Behavioral Factors Contributing to Reengineering Risks", Journal of Management Information Systems, 12, 9-36.

Digital Planet - The Global Information Economy. World Information Technology and Services Alliance (WITSA), 1998.

Dos Santos B.L. (1991), "Justifying Investments in New Technologies", Journal of Management Information Systems. 7,71-90.

Farbey B., Land F., and Target D. (1992), "Evaluating investments in IT". Journal of Information Technology. 109-122.

Heikkilä J. (1995), "Adoption of Learning Intensive Technology - The case of personal computers", Helsinki School of Economics, A-104.

Hochstrasser, B. (1990), "Evaluating IT Investments: Matching Techniques and Projects", Journal of Information Technology, 5, 215-221.

Kivijärvi, H. (1997), "A Substance-Theory-Oriented Approach to the Implementation of Organizational DSS", Decision Support Systems, 20, 215-241

Kivijärvi, H. and Tuominen, M. (1999), "Computer Based Intelligence, Design, Choice, Implementation, and Control of Intangible Investments Projects", Proceedings of the Thirty-Second Annual Hawaii International Conference on System Sciences.

Lester, S. and Willcocks, L. (1993), "How do organizations evaluate and control information systems investments? Recent UK survey evidence", Paper for the IFIP WG8.2. working conference

Markowitz, H. (1952),"Portfolio Selection", Journal of Finance, March 1952, 77-91.

Mills, R.W. (1988),"Capital budgeting - The state of the art", Long range planning, 21, 76-81.

Peffers K., and Saarinen T. (1993), "Measuring The Business Value of IT Investments: Inferences From A Study Of Senior Bank Executives",Fifh Workshop on Information Systems and Economics (WISE).

Powell P. (1992), "Information Technology Evaluation: Is It Different?", Journal of the Operational Research Society, 43, 29-42.

Saarinen, T. and Vepsäläinen, A., P., J. (1994), "Procurement Strategies for Information Systems", Journal of Management Information Systems, 11, 187-208

Saaty, T.L. (1999), "Decision Making for Leaders", RWS publications, Pittsburgh, PA,

Santhanam, R. and Guimares, T. (1995), Assessing the quality of institutional DSS". European Journal of Information Systems, 4, 159-170.

Shapiro, A.C. (1991), "Modern Corporate Finance", Macmillan Publishing Company.

Ward, J. and Taylor, P. and Bond, P. (1996), "Evaluation and Realization of IS/IT benefits: an empirical study of current practice", European Journal of Information Systems, 4, 214-225.

Wehrs, W.E. (1999), "A Road Map for IS/IT Evaluation", in Measuring Information Technology Investment Payoff: Contemporary Approaches, edited by Mahmood and Szewczak, Idea Group Publishing.

Wen, H.J. and Sylla, C., (1999), "A Road Map for the Evaluation of Information Technology Investment", in Measuring Information Technology Investment Payoff: Contemporary Approaches, edited by Mahmood and Szewczak, Idea Group Publishing. 